\title{
Ecological evaluation of technologies for application of plant protection measures by spraying method
}

\author{
Anatolij Lysov", and Timur Kornilov \\ All-Russian institute of plant protection (FSBSI VIZR), Podbelskogo, 3, Pushkin, St. Petersburg, \\ 196606, Russia
}

\begin{abstract}
The biological and economic effectiveness of plant protection measures depends not only on the correct choice of pesticide, but also on the quality of its application to the processed target objects. The article discusses the results of assessing the quality of applying herbicides by spraying using low-volume spraying technology, ULV spraying without forced and forced precipitation of small droplets, and treatment with cold aerosol. To assess the impact of the quality of the application of plant protection products on the environmental safety of the use of herbicides, two main indicators were used: - uniform distribution of the working fluid over the treated area: - the amount of drift of small drops from the treatment area. The analysis of methodological approaches and regulatory documents for assessing the potential risk of pesticides for the environment in European countries and in Russia is given.Based on the obtained experimental data on the coefficients of variation in the distribution of the drug over the effective coverage width, an expert assessment of the drug overuse was carried out using various technologies. An expert assessment of the drift of small drops of the working fluid from the treatment zone was also carried out. A comparative assessment of technologies was carried out according to the indicated environmental safety indicators for the use of the herbicide Gezagard WP on potato plantings.
\end{abstract}

\section{Introduction}

When using plant protection products, along with the positive effect of preserving the crop, we always have environmental risks from their use for the environment and wildlife. When registering new plant protection products, the norms for applying pesticides $(\mathrm{kg}, \mathrm{l}, \mathrm{mg}$, $\mathrm{ml} . / \mathrm{ha}$ ), and the waiting time for a safe exit to the field, depending on the toxicity and physical-chemical properties of the drug, are regulated taking into account the biological effectiveness and environmental safety.

For the environmental assessment of plant protection measures, in most cases, indicators such as pesticide load per hectare or environmental and economic assessment of

\footnotetext{
*Corresponding author: lysov4949@yandex.ru
} 
technologies and measures for plant protection in optimization systems for plant growing and fruit growing are used [1].

Due to the continuous improvement of the range of plant protection products, the emergence of new classes of effective active ingredients of herbicides, insecticides, fungicides with low drug consumption rates from tens to hundreds of grams per hectare instead of kilograms per hectare, the criterion widely used as a pesticide load per hectare creates in the new conditions a misconception about the decrease in the intensity (frequency) of the use of certain groups of pesticides.

In this connection, at present, the most widely used for environmental assessment of plant protection measures are the use of integrated indicators for quantitative and qualitative data on the intake of active substances and their decomposition products in soil, water, air, and crop products.

In European countries, in accordance with the recommendation of the OECD (Organization for Economic Co-operation and Development), the computer program SYNOPS 1.2 has been developed and used for modeling environmental risks from pesticides, taking into account the technologies for their use.

Risk assessment from plant protection technologies, according to the developed model, is carried out using the following indicators:

- the spectrum of action of pesticides, their physicochemical and ecotoxicological properties;

- comparison of active substances;

- determination of the amount of substance that has got into the treated plants, soil, surface water, taking into account the technology of introducing each drug;

- determination of the timing of the degradation of protective equipment in soil, air, surface water;

determination of biological risk indicators for each application technology and active substance used [2].

At the All-Russian Institute for Plant Protection (VIZR) N.N. Semenova with G.I. Sukhoruchenko developed domestic programs PESTINS and PESTINL for computer simulation of the behavior of pesticides in agrocenoses of agricultural crops to assess the prolonged action and hazard of pesticides [3]. These programs make it possible to determine the nature of degradation and localization of pesticides in the components of the soil - plant system, as the degree of toxic effects on target objects taking into account biological effectiveness and environmental hazard, as well as to assess the local risks of using pesticides $[4,5]$.

Academic V.A.Zakharenko for environmental assessment of technologies for the use of plant protection products in optimizing the phytosanitary condition of agrocenoses proposed as the main criteria to use the indicator Ld50, multiplied by the processing area of the used pesticide groups, as well as their half-life [6].

However, existing programs do not fully take into account the technological parameters of the quality of the application of plant protection products by spraying onto the treated targets. It should be noted that the quality indicators for the application of working fluids associated with ensuring the uniformity of the distribution of drugs over the treated area and the reduction of unproductive losses of protective equipment to the environment due to the environmental assessment of the technology of applying pesticides by spraying are of great importance. demolition and evaporation of small drops.

The first indicator has a significant impact on the biological effectiveness of protective measures, the contamination of crop products with residual pesticides, the development of resistance of harmful objects to applied pesticides, as well as the level of environmental risk. The uniformity of the distribution of plant protection products at the effective capture width depends on regular and random factors. Random factors include the dynamic 
vibrations of the boom in the vertical and horizontal planes as the sprayer moves across the field, as well as weather conditions affecting the evaporation and drift of droplets of sprayed liquid from the treatment zone [7].

Obviously, the unevenness of the macro relief of the soil surface, affecting the position of the sprayers relative to the treated surface, as well as the effect of turbulent air flows during gusts of wind on droplets of dispersible liquid, is very difficult to take into account.

Regular factors that can be controlled include the deviation of the rate of flow of the working fluid from the set area per unit due to inaccurate dosing, deviation of the flow rate between the individual sprayers, the height of the rod to the surface to be treated, the spacing of the sprayers, flaws and overlapping with the technological passages of the spraying unit. According to the results of experimental data on the working fluid deposits at the effective working width of the spraying equipment, it was found that the ratio of the sum of the areas expressing the cost overrun of the working fluid in the considered section of the working width to the average value of the deposit is associated with the variation coefficient the following dependency:

$$
\frac{\Sigma \Delta S_{t}}{\bar{S}}=0,4 \vartheta
$$

where $\mathrm{S}$ is the overexpenditure of the working fluid relative to the average amount of deposition at the effective working width;

$\vartheta$ - coefficient of variation of uneven distribution.

From this we can conclude that for each percent of the coefficient of variation there are $0.4 \%$ of unproductive losses of the total flow rate of the drug's working fluid [6]. In this connection, we conducted comparative tests to evaluate the technology of low-volume spraying with a working fluid consumption rate of $2001 /$ ha and ultra-low-volume spraying with a working fluid consumption of $10 \mathrm{l} /$ ha to protect potato crops and grain crops from weeds and aerosol technology using a generator with adjustable dispersion to assess the uniformity of the distribution of the drug over the effective capture width.

\section{Materials and methods}

To apply the low-volume spraying technology, a boom sprayer equipped with Lechler IDK 11003 injection nozzles was used, and for the ULV spraying technology, a sprayer equipped with rotating perforated drums with a spacing of 1.2 meters on boom sections. The working body of the sprayer for ULV spraying is a rotating perforated drum that structurally ensures the execution of the spraying process in two modes: with forced precipitation of small drops and without forced precipitation of small drops [8]. For aerosol treatment, an aerosol generator with adjustable dispersion was used

Evaluation of the quality of spraying was carried out in accordance with the requirements of GOST R 530532008 Plant protection machines Sprayers Test methods, EN 12761-1; 2001, Land- und Forstmaschinen - Pflanzenschutzgeräte zum Ausbringen von Pflanzenschutzmittein und flüssigen Düngemittechultz, $1 \mathrm{Um}$. Agricultural and forestry machines. Sprayers and spreaders for applying protection products and mineral fertilizers. Part 1 and EN 12761-3; 2001 "Agricultural machines and machines for forestry. Various plant protection devices for the application of plant protection products, environmental protection "using certified test equipment Test Sprayer" Herbst 1000 "made in Germany. As a model fluid, a $1 \%$ solution of uranium in water was used. To measure meteorological parameters (air temperature, wind speed and direction), the Skywatch Xplorer 4 instrument was used. For measurements and counting by droplet size classes and coverage density of indicator cards, a scanning system with software was used. 


\section{Results and discussion}

For field boom sprayers with slotted flat-spray nozzles, the European norm allows the uneven distribution of the working fluid over the spray boom width, expressed by the coefficient of variation, in the stationary position $-7 \%$, and when the sprayer moves $-9 \%$. We have assessed the uneven distribution of the working fluids of herbicides in the treatment of planting potatoes against weeds when comparing two spraying technologies: small-volume spraying, ULV spraying with forced and non-forced dropping, aerosol treatment with mechanical dispersion of the working fluid and transportation their air flow. These indicators were necessary for a comparative assessment of the environmental safety of various technologies when introducing plant protection products. As a criterion, we used a normative indicator of the uniformity of distribution of plant protection products at a given rate of drug consumption per hectare equal to one. Based on the results of assessing the uneven distribution of the drug over the effective capture width, the following values of the coefficient of variation were obtained, which are presented in Table 1.

Table 1. Uneven distribution of the drug over the effective working width at various pesticide application technologies

\begin{tabular}{|l|c|c|}
\hline \multicolumn{1}{|c|}{ Processing technology } & $\begin{array}{c}\text { Variation } \\
\text { coefficient, } \%\end{array}$ & $\begin{array}{c}\text { Median-mass diameter } \\
\text { of droplets, microns }\end{array}$ \\
\hline Low volume spraying & 10.0 & 470 \\
\hline ULV spraying without forced precipitation & 20.0 & 142 \\
\hline $\begin{array}{l}\text { ULV spraying with forced precipitation of } \\
\text { drops }\end{array}$ & 14 & 142 \\
\hline Aerosol treatment & 90 & 16 \\
\hline
\end{tabular}

From table 1 it is seen that when using forced precipitation of droplets, the uniformity coefficient of variation improves due to the directed air flow created by the fan, small droplets are deposited on the treated surface and a more uniform distribution of the working fluid over the spray width is ensured, which clearly visible in Fig.1a and $1 \mathrm{~b}$.

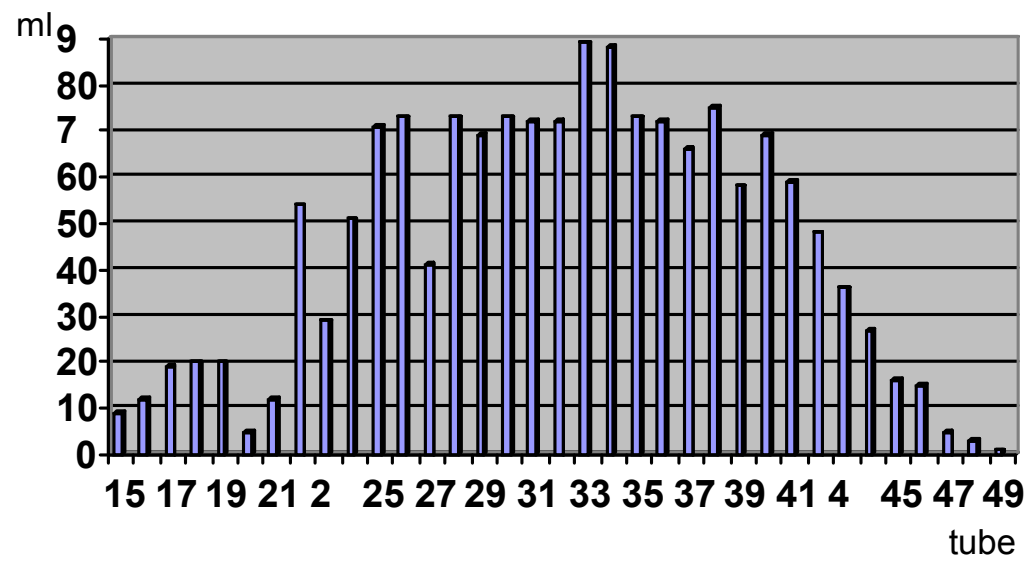

Fig. 1a. Distribution of liquid over the spray width without a fan for forced precipitation of droplets 


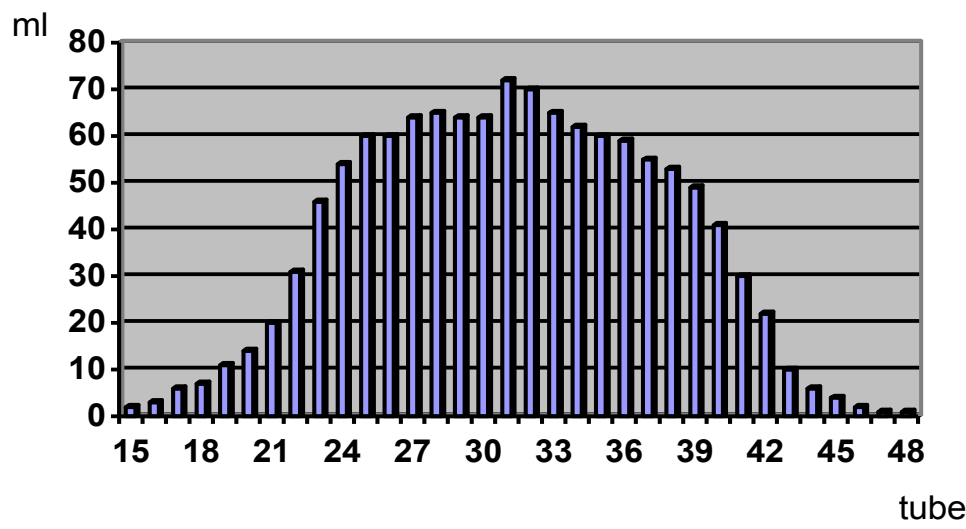

Fig. 1b. Distribution of liquid along the width of the spray nozzle with forced precipitation of droplets We see the worst indicator of the uniformity of the distribution of settled droplets when using aerosol treatment (cold aerosol), which according to the test results was:

$$
\gamma=100 \frac{\delta}{\bar{Q}} 89,77 \%
$$

The deposition graph for the effective capture width is shown in Fig.2.

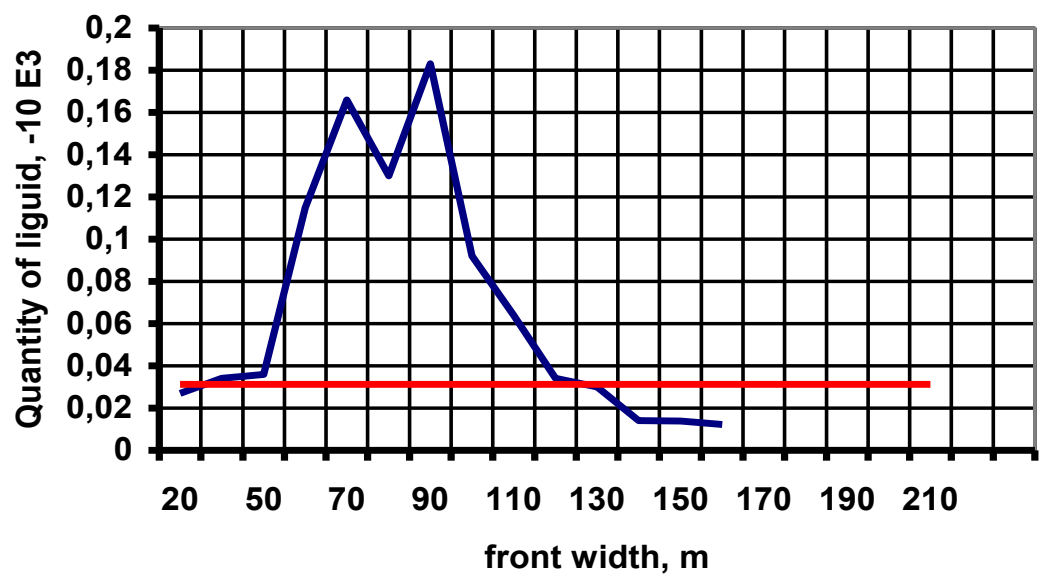

Fig. 2. Distribution of the amount of settled liquid over the wavelength of the aerosol generator with adjustable dispersion

Based on the obtained values of the coefficient of variation of the uniformity of the distribution of the drug on the effective capture width with various technologies for applying the Gezagard WP herbicide on potatoes and taking into account the regulated rate of drug administration and reduced by 25 percent, the following values of the coefficient of drug overuse in individual sections were obtained fields presented in table 2.

A comparative analysis of the values of the drug over-consumption coefficients with various technologies for applying herbicides shows that the use of aerosol technology is unacceptable. since we have great risks for the environment and contamination of crop products with residual pesticide due to significant overdoses of the drug in certain areas of the field. 
Table 2. The values of the coefficient of cost overrun of the drug with different application technologies

\begin{tabular}{|l|c|c|}
\hline The name of the technology & $\begin{array}{c}\text { The consumption rate of } \\
\text { the drug, } \mathrm{kg} \text { per ha/mg } \\
\text { per } 1 \mathrm{~m}^{2}\end{array}$ & $\begin{array}{c}\text { The coefficient of drug } \\
\text { overrun in individual } \\
\text { sections of the field }\end{array}$ \\
\hline Low volume spraying & $3.5 / 350$ & 1.04 \\
\hline $\begin{array}{l}\text { ULV spraying without forced } \\
\text { precipitation of drops }\end{array}$ & $3.5 / 350$ & 1.08 \\
\hline $\begin{array}{l}\text { ULV spraying with forced } \\
\text { precipitation of drops }\end{array}$ & $3.5 / 350$ & 0.79 \\
\hline $\begin{array}{l}\text { ULV spraying with forced } \\
\text { precipitation of drops and a } \\
\text { reduced rate of the drug by } 25 \%\end{array}$ & $2.625 / 262.5$ & 1.36 \\
\hline Aerosol technology & 3.5 & 1.02 \\
\hline $\begin{array}{l}\text { Aerosol technology with a } \\
\text { reduced consumption rate of } 25 \%\end{array}$ & 2.625 & \\
\hline
\end{tabular}

The technology of ULV spraying has the prospect of application only under the condition of using forced precipitation of drops of the working fluid and ensuring a reduction in the consumption rate of the drug by at least $25 \%$. A comparative analysis of the biological and economic efficiency of this technology with low-volume spraying shows that this technology provides high biological effectiveness of protective measures and economic efficiency [9].

Calculations of economic efficiency showed that the technology of UMO application with forced precipitation of droplets can reduce the cost of protective measures by 550 rubles $(8 €)$ per hectare by reducing the recommended application rates by $25 \%$ and reducing the cost of transporting and refueling the working fluid of the sprayer when applying the Gezagard herbicide.

In the environmental assessment of technologies for introducing plant protection products, one should also pay attention to the size of the droplets of the dispersible working fluid. The size of the drops significantly affects the drift and evaporation of the drops, as well as the rate of penetration of the drug into the biomass of plants.

When evaluating the technologies for applying herbicides, we obtained data on the dynamics of decomposition of the Gezagard WP preparation in the green mass of potatoes using the low-volume spraying technology using IDK 120-03 injection nozzles with a median droplet diameter of 470 microns and the ULV spraying technology with compulsory sedimentation of droplets with a median-mass diameter of a droplet of $142 \mu \mathrm{m}$, which are shown in Fig. 3.

On the first day after treatment with the ULV spraying technology with forced precipitation of droplets, we observe a $35 \%$ increase in the amount of the drug in the biomass of plants in comparison with the technology of low-volume spraying, and this dynamics persists up to seven days after treatment. This is due, first of all, to a droplet size that is more than 3 times smaller with ULV technology, as a result of which the coating density of the treated surface increases by 27 times. On day 28, the residual amounts of the active substance of the drug in the plant mass are the same. This is due to degradation of the herbicide and a decrease in toxicity due to an increase in plant biomass. 


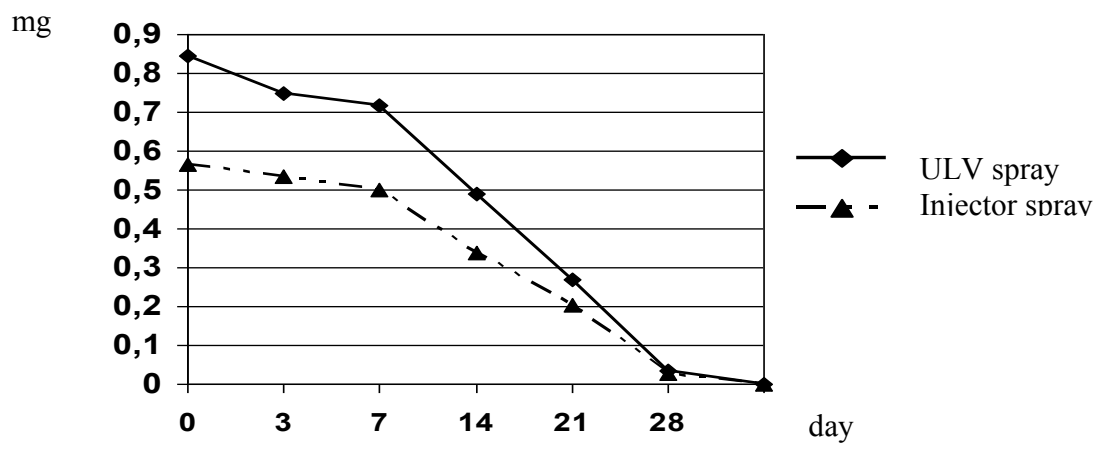

Fig.3. The dynamics of decomposition of the herbicide Gezagard in the green mass of potatoes

In order to reduce environmental risks for non-target organisms when using plant protection products caused by the removal of small drops from the treatment area, the main regulatory documents governing the safety of pesticides are adopted in European countries: For example, in Germany, the following regulations apply for agricultural producers:

Regulations NW 600-609 "Protection of aquatic organisms, which includes:

- NW-600-501 rigidly fixed processing distances;

- NW -602-603 flexible processing distances to water sources and water bodies, which are divided by risk categories $\mathrm{A} / \mathrm{B} / \mathrm{C} / \mathrm{D}$;

- NW 605-609 treatment distances in accordance with the class of spray guns to reduce drift by $90 / 75 / 50 \%$ (the possibility of reducing distances due to the use of sprayers with reduced losses of working fluid, as well as the width of ponds and the state of plantings).

Prescriptions NS 610-62319 "Protection of terrestrial non-target organisms (insects, plants on non-agricultural land)".

In these requirements, a point assessment is used to assess the risk category for water bodies and non-target objects using pesticides by the spraying method.

When using certified sprayers on spraying equipment in modes that ensure drift reduction by $90 \%-10$ points, $75 \%-6$ points, $50 \%-3$ points. The presence of a body of water bordering the treated field with running water with a minimum width of 3 meters is estimated at 6 points. Taking into account the presence and condition of plantations at the boundary of the reservoir (densely developed foliage along the entire height of the plantations with a width of at least 1 meter, the height of the treated plants and the height of the sprayer installation is at least 1 meter, and in the gardens: the height of the trees and shrubs is at least 1 meter) -3 points.

Based on the summation of the scores, the risk category for introducing pesticides in fields with different agrolandscapes is determined in accordance with table 3 .

Table 3. Raiting risk categories

\begin{tabular}{|c|c|}
\hline Risk Category & Minimum Points \\
\hline A & 20 \\
\hline B & 10 \\
\hline C & 6 \\
\hline D & 3 \\
\hline
\end{tabular}

In the Russian Federation, according to SanPiN 1.2. 250-10 "Hygiene requirements and safety of testing, storage, transportation, sale, use, disposal, disposal of pesticides and agrochemicals", sanitary protection zones must be observed to prevent pesticides from entering water bodies. Do not use pesticides near water sources or ponds. In case of surface 
treatment of plants with pesticides by spraying, the sanitary protection zone should be at least $300 \mathrm{~m}$, and with aerial spraying $-1000 \mathrm{~m}$.

It is forbidden to pesticide aerial treatment of sites located closer than $2 \mathrm{~km}$ from settlements, territories of state reserves, natural (national) parks, reserves, fishery reservoirs and sources of domestic - drinking water supply. In this connection, it is necessary to choose the operating modes of the working bodies of the spraying equipment in order to minimize the demolition of small drops outside the treated areas.

To determine the drift value when setting up the experiments, we used the data of the Federal Biological Department (BBA) for Lechler injection nozzles, and for a rotating perforated drum without forced and forced droplet deposition based on the obtained experimental results.

In Germany, in accordance with the requirements of the international standard ISO / DIS 22856-1 "Equipment for crop protection-Laboratory measurement methods of spray drift" BBA, the classes of drift (drift) reduction for injection nozzles by $90 \%$ are determined at an operating pressure of 1.0-2.0 bar, the speed of the process $5-10 \mathrm{~km} / \mathrm{h}$ with the flow rate of the working fluid mainly from 100 to 230 1/ha: $75 \%$ at working pressures from 2.0 to $3.0 \mathrm{bar}$, speed $5-10 \mathrm{~km} / \mathrm{h}$ and working fluid flow rates from 120 to 310 and more $1 / \mathrm{ha}$, and $50 \%$ at operating pressures from 3.0-5.0 bar, driving speeds of $5-10 \mathrm{~km} / \mathrm{h}$ and normal working fluid flow rate from 140 to 470 1/ha

For a comparative assessment of technologies in terms of the drift of small droplets, we adopted a standard drift index equal to one, the excess of which characterizes the level of increased risk of using plant protection products. The obtained values are presented in table 4.

Table 4. Demolition Technology Assessment

\begin{tabular}{|l|c|c|}
\hline \multicolumn{1}{|c|}{ Name of technology } & Drift class, $\%$ & Drift coefficient \\
\hline Low-volume spraying IDK 120 03 & 90 & 1.1 \\
\hline ULV spraying without forced precipitation of drops & 25 & 1.75 \\
\hline ULV spraying with forced precipitation of drops & 90 & 1.1 \\
\hline $\begin{array}{l}\text { ULV spraying with forced precipitation of drops } \\
\text { and a reduced rate of the drug by 25\% }\end{array}$ & 90 & 1.1 \\
\hline Air curtain sprayer & 80 & 1.2 \\
\hline
\end{tabular}

From the data obtained, it can be concluded that the technology of low-volume spraying and ULV spraying with forced precipitation of small droplets with a reduced consumption rate of the drug by $25 \%$ provide a more environmentally friendly application of herbicides in the fight against weeds on potato plantings.

Aerosol technology was excluded from the assessment, as indicators for drift above 500 meters exceeded the permissible norm of 300 meters.

\section{Conlusion}

The technology of low-volume spraying and ULV spraying with forced precipitation of small drops with a reduced consumption rate of the drug by $25 \%$ provides a more environmentally friendly application of herbicides in the fight against weed vegetation on potato plantings.

A comparative analysis of the values of the drug over-consumption coefficients with various technologies for applying herbicides shows that the use of aerosol technology is unacceptable. Since we have great risks for the environment and contamination of crop products with residual pesticide due to significant overdoses of the drug in certain areas of the field. 


\section{References}

1. V.A. Zaharenko, N.R. Goncharov, O.P. Kashirskij, V.I. Dolzhenko. Ecological and economic assessment of the use of technical means, technologies and measures for plant protection in the system of phytosanitary optimization of crop production in the conditions of transition (Methodological recommendations). Saint-Peterburg, P.12. (2000).

2. D. Shpaar, and others. Plant protection in sustainable land use systems,2, 373 (2003)

3. N.N. Semenova. in the collection "Mathematical models of natural and anthropogenic eco-systems", dedicated to the memory of $R$. A. Poluektov, AFI, 126141.(2014)

4. N.N.. Semenova, K.V. Novozhilov, G.I. Suhoruchenko. J. Vestnik zashchity rastenij, 3, 3-9 (2012)

5. V.N Kolupaev., V.S. Gorbatov. December 16-20, 2013 Saint Petersburg. Phytosanitary optimization of agroecosystems. Materials of the Congress in three volumes. 2, 193-194, (2013)

6. V.A. Zaharenko, G.V. Sudarikov, A.V. Zaharenko. 80, (2001).

7. A.K. Lysov, 164.(2019).

8.Patent RF №2574678 «Atomizer» V.A. Pavlyushin, V.N. Andreev, D.V. Vegera, T.V. Kornilov, A.K. Lysov http://www.freepatent.ru/patents/2574678

9. N.R. Goncharov, A.K. Lysov, N.I. Naumova, T.V. Kornilov. J. Economy of agricultural and processing enterprises. 3 P. 54-57.(2019):// doi.org/10.31442/0235-24942019-0-3-54-57 